\title{
Um relato de experiência na tradução técnico-científica em educação
}

\author{
David Wesley Amado Duarte* \\ Wanderlucy Czeszak ${ }^{*}$
}

\section{Resumo}

Este artigo trata de um relato de experiência sobre o processo de tradução de um artigo científico. $\mathrm{O}$ artigo original foi traduzido da língua inglesa para a língua portuguesa. Inicialmente, a tradução envolveu a ideia de dar oportunidade a estudantes de graduação entrarem em contato com um trabalho importante. $\mathrm{O}$ artigo original tem diferenças significativas dos trabalhos brasileiros, incluindo estrutura e forma de apresentação, tratando-se de um guia passo a passo para a realização de Revisões Sistemáticas de Literatura. Os possíveis benefícios resultantes da tradução do artigo são: aproximar a comunidade de língua portuguesa de trabalhos internacionais; trazer a essa comunidade um método de trabalho que organiza e dá rigor científico às Revisões Sistemáticas de Literatura.

Palavras-chave: Tradução. Artigos Científicos. Tradução Técnica.

\section{An experience report in technical-scientific trans- lation}

\section{Abstract}

This article brings an experience report presenting the process of translation of a scientific article. Original article was translated from English to Portuguese. Initially, translation involved the idea of giving graduate students the opportunity to read an important work. Original article has

* Professor do Instituto Federal do Ceará (IFCE), campus Crato. Mestre em Computação Aplicada, com ênfase em Informática Educativa pela Universidade Estadual do Ceará (UECE). Coordena, atualmente, o curso de Bacharelado em Sistemas de Informação do IFCE, campus Crato.

** Professora da Universidade Anhembi Morumbi (UAM), em São Paulo - SP. Doutora em Educação e Tecnologias pela Universidade de São Paulo. 
significant differences compared to Brazilian works, including structure and form of presentation. Original article is a step-by-step guide for the accomplishment of Systematic Literature Reviews. Potential benefits resulting from the translation of the article are to bring the Portuguese -speaking community closer to international works and to bring to this community a method of work that organizes and gives scientific rigor to the Systematic Literature Reviews.

Key-words: Translation. Scientific Articles. Technical Translation.

\section{Un relato de experiencia en la traducción técnico-científica en educación}

\section{Resumen}

Este artículo trata de un relato de experiencia sobre el proceso de traducción de un artículo científico. El artículo original se tradujo del inglés al portugués. Inicialmente, la traducción implicó la idea de dar la oportunidad a los estudiantes de graduación de entrar en contacto con un trabajo importante. El artículo original tiene diferencias significativas de los trabajos brasileños, incluyendo estructura y forma de presentación, tratándose de una guía paso a paso para la realización de Revisiones Sistemáticas de Literatura. Los beneficios potenciales resultantes de la traducción del artículo son: acercarse a la comunidad de lengua portuguesa de trabajos internacionales; traer a esta comunidad un método de trabajo que organiza y da rigor científico a las Revisiones Sistemáticas de Literatura.

Palabras clave: Traducción. Artículos científicos. Traducción técnica.

\section{Introdução}

A internet permitiu o acesso a muitos tipos de materiais. Especificamente no campo científico, massificou a divulgação de pesquisas por intermédio de diversas coleções de periódicos de distribuição gratuita. Da mesma maneira, tornou-se comum o contato com trabalhos desenvolvidos em países estrangeiros, escritos em muitas línguas. Aqueles escritos em língua inglesa são os mais comuns, incluindo trabalhos publicados em muitos periódicos brasileiros (PACKER, 2014).

No Brasil, estudantes universitários têm grande dificuldade de leitura em língua inglesa, resultado de problemas de aprendiza- 
gem nos ensinos fundamental e médio (MICCOLI, 2007). Uma tradução minimiza os efeitos desse problema, pois o tradutor considera o público-alvo ao levar informações importantes e necessárias à cultura de chegada (BENITES; PRIETO, 2013).

Traduções técnicas envolvem a tradução de documentos que apresentem termos específicos de determinada área de especialidade e são caracterizados por frases e parágrafos curtos, objetividade, voz passiva e conclusões parciais em cada item abordado, como artigos científicos (POLCHLOPEK; AIO, 2010).

Ao ler o artigo $A$ Guide to Conducting a Standalone Systematic Literature Review ${ }^{1}$ (OKOLI, 2015), percebemos quão importante seria permitir que nossos alunos de graduação pudessem ter acesso a esse trabalho. E não só a nossos alunos, mas a toda a comunidade de língua portuguesa interessada em trabalhar com Revisões Sistemáticas de Literatura nas áreas de Ciências Sociais e outras áreas correlatas. Assim, um dos autores deste trabalho traduziu o artigo que, em língua portuguesa, tem o título: Guia de Revisão Sistemática de Literatura.

O material traduzido é um guia, no formato de tutorial, que apresenta uma série de passos que o autor defende como sendo necessários para uma Revisão Sistemática de Literatura suficientemente rigorosa e com caráter científico (OKOLI, 2015).

Com o objetivo de descrever o processo e apresentar os benefícios da tradução para os nossos alunos de graduação e para toda a comunidade de língua portuguesa, este artigo traz um relato de experiência de um dos autores deste trabalho, incluindo as impressões a respeito do que foi encontrado no original. A descrição envolve desde o primeiro contato com o trabalho e sua leitura, até os planos que levaram à tradução e publicação do mesmo em língua portuguesa.

Este artigo está organizado em seções. A seção seguinte traz como referencial teórico os trabalhos de Polchlopek e Aio (2010) e Benites e Prieto (2013), tratando dos conceitos e características referentes à tradução técnica e a responsabilidade do tradutor. A

Disponível em: < http://aisel.aisnet.org/cais/vol37/iss1/43/>. 
terceira seção apresenta um pouco da experiência de um dos autores deste trabalho como tradutor, descrevendo os convites e os processos de outras traduções realizadas por ele. A quarta seção relata como ele teve acesso ao artigo e como surgiu o interesse em traduzi-lo. A quinta seção exibe a estrutura do artigo original, suas diferenças para os artigos brasileiros, e as dificuldades que ele encontrou para traduzir determinados termos de forma a dar melhor entendimento em língua portuguesa. Por fim, nas considerações finais há uma curta reflexão acerca dos benefícios desta tradução, bem como, a respeito da importância de permitir o acesso a trabalhos estrangeiros à comunidade de língua portuguesa.

\section{Tradução e responsabilidade do tradutor}

A imagem que as pessoas geralmente têm é que, para traduzir um texto, é necessário "apenas" conhecer um "dicionário" de palavras em determinada língua estrangeira e ter formação acadêmica ou experiência na área do texto original.

Nesse sentido, para Polchlopek e Aio (2010, p. 102) “[...] a tradução técnica, ao contrário do que comumente se imagina, não é um terreno árido, sem vida, no qual é suficiente o domínio dos idiomas, bem como a terminologia da área de tradução”.

Dizem ainda as autoras (op. cit., p. 104):

Se traduzir é, à parte os termos teóricos, transpor um texto de uma língua para outra, não se pode esquecer de que a língua é parte integrante da cultura, ou seja, os textos técnicos também estão expostos a variantes culturais estilísticas, lexicais, sintáticas ou mesmo variantes internas à própria área técnica em que se está traduzido (sic) devido a diferenças no grau de desenvolvimento tecnológico entre uma cultura e outra, por exemplo. Conhecer tais especificidades deve fazer parte do processo de tradução tanto quanto o domínio da terminologia em questão, no sentido de buscar um texto funcionalmente adequado para o leitor-destinatário ou grupo.

Assim, a tradução de um texto de qualquer modalidade é muito mais do que simplesmente transliterar palavras. Deve levar em consideração que o conjunto de palavras utilizado deve tornar 
inteligível características próprias de uma cultura para outra. Para além da preocupação com cada termo específico, o tradutor deve dar um sentido a cada termo, adequando-o para o público-alvo.

Nesse contexto, os termos técnicos estão no extremo oposto aos termos de textos literários: "O termo técnico polariza, de um lado, os textos chamados literários ou poéticos e, de outro, todos aqueles que tenham caráter de manual, documento, artigo e que empreguem uma terminologia representativa de uma determinada área de especialidade" (IDEM, p. 105). Na verdade, o termo "técnico" se refere às características estilísticas do texto onde predominam:
a) tempo presente com a função de atingir a objetividade;
b) uso de frases curtas;
c) ausência de ambiguidade;
d) pouco uso de adjetivação valorativa;
e) emprego de voz passiva;
f) parágrafos curtos;
g) dados estatísticos;
e) conclusões parciais para cada item abordado;
f) termos técnicos.

Dessa forma, a tradução também transmite características culturais que são responsáveis pelo entendimento das mensagens tanto no formato oral como escrito, subjacente ao conteúdo relevante transmitido por quem fala, e "só através de uma análise minuciosa das referências culturais implícitas a certas estruturas do texto que é possível identificar esses elementos que representam a cultura" (BENITES; PRIETO, 2013, p. 4).

Para Benites e Prieto (2013, p. 2):

[...] a cultura não é um fenômeno material e não consiste de coisas, pessoas, comportamentos, ou emoções. Cultura é, antes, uma organização desses elementos, a forma como as pessoas os tem em mente, os seus modelos, para perceber, relacionar e interpretá-los de uma forma. 
Tais elementos e contextos culturais fazem das palavras estruturas "animadas", com uma variedade de sentidos que, em traduções automáticas acabam gerando inadequações, termos que parecem "truncados", não naturais ou de difícil assimilação, por trazerem a ideia de imobilidade e rigidez mecânica da língua (SOBRAL, 2008 apud BENITES; PRIETO, 2013).

Além disso, o texto escrito carrega toda uma pluralidade epistemológica, resultante de influências vividas pelo sujeito, de natureza social, política, cultural e histórica (OLIVEIRA, 2007) que tornam a tradução uma espécie de recriação da obra traduzida, na medida em que o tradutor exerce sua capacidade de escuta diante da voz do autor estrangeiro, interpretando essa voz para outro idioma, buscando levar em conta o máximo possível de sua carga original, e a transportando para esse outro idioma, no caso a língua portuguesa.

Ressalta-se que o tradutor é também um investigador, dado que ele busca expressões que melhor representem as variações do trabalho original. Um bom texto final deve fazer sentido na língua-alvo, com os denominados termos "técnicos" adequadamente definidos para evitar desvios ou dificuldades de entendimento para os leitores. Assim, além dos conhecimentos lexicais e sintáticos da língua-fonte, traduzir um texto técnico-científico exige estar familiarizado com os termos utilizados, o tipo e a estrutura textual, bem como, com os aspectos culturais subjacentes (POLCHLOPEK; AIO, 2010).

De fato, o tradutor, quando tem em mãos um trabalho a traduzir, tem a responsabilidade de não transcrever palavras isoladas, mas contexto, cultura, informação e conhecimento.

Nesse sentido, Mello relata suas dificuldades e algumas reflexões a partir da experiência de tradução de um texto teatral francês de 1789, chamado "A Revolução", de Ariane Mnouchkine. Nesse caso, por se tratar de um texto teatral, cujos aspectos metafóricos e expressivos estão fortemente presentes, há dificuldades referentes à necessidade de se manter nuances poéticas e de humor. Passar para a tradução no papel uma obra teatral é como tornar estático e con- 
creto algo fluido e em constante estado de movimento (OLIVEIRA, 2007). Ao final do seu relato, Mello (2013, p. 145) desabafa:

\begin{abstract}
Assim, relendo hoje o meu trabalho de anos atrás, insatisfeita com o resultado, percebendo como poderia ainda melhorar o texto hoje, constato que o tradutor realiza, com o escritor traduzido, a descida aos infernos da criação artística, com tudo o que pode haver nela de silêncio, de sofrimento, de "não ditos", de riqueza e de ausência de palavras, de indeterminação, de ambiguidade. E, durante o seu trabalho, ele participa um pouco do mistério da arte de escrever...
\end{abstract}

Costa e Nascimento (2017), por sua vez, adotam a estratégia da tradução do português para o inglês do conto "A Cartomante", de Machado de Assis, numa turma de graduação em Tradução da Universidade Federal da Paraíba, no intuito de possibilitar aos alunos o desenvolvimento de competências tradutórias, além de um olhar crítico sobre as funções do tradutor. As autoras salientam desafios com relação à busca da preservação da formalidade do texto original, além do que já apontado por Mello (2013) e também observado no relato exibido no presente artigo, como dificuldades referentes às diferenças culturais e termos específicos nos diferentes idiomas, mantendo o cuidado de não se distanciar do texto original.

A experiência é, portanto, fator importante na atividade de tradução, pois a cada novo trabalho, vão se desenvolvendo habilidades e se aprimorando a prática, como podemos observar por meio do relato das primeiras atividades de tradução de um dos autores do presente trabalho.

\title{
3 Primeiras traduções
}

No ano de 2015, o Professor João Mattar fez um convite aberto, por meio das redes sociais, para a tradução de um livro. Um dos autores deste artigo demonstrou interesse em participar e foi convidado. Logo depois do convite, criou-se um grupo no Facebook com uma equipe que passou a trabalhar colaborativamente, 
usando arquivos no Google Drive e trocando e-mails. Cada um dos participantes escolheu uma parte do livro e começou a trabalhar. $\mathrm{O}$ livro, "Educação a Distância Online: construindo uma agenda de pesquisa”, organizado pelos renomados autores Olaf Zawacki-Richter e Terry Anderson, com prefácio de Otto Peters, foi traduzido por intermédio de uma parceria entre a Associação Brasileira de Educação a Distância (ABED) e a Editora Artesanato Educacional.

No livro Educação a Distância Online, este autor traduziu a Introdução, onde estão descritas as áreas de pesquisa em Educação a Distância, uma síntese dos "problemas, oportunidades, questões e desafios associados a cada uma das áreas principais para criar uma agenda de pesquisa guiada empiricamente" (ZAWACKI-RICHTER; ANDERSON, 2015, p. 9). Além disso, há um sumário executivo com uma revisão das ideias, conteúdos e abordagens principais de cada um dos capítulos escritos por proeminentes autores e pesquisadores em $\mathrm{EaD}$.

No ano seguinte, foi feito um novo convite, dessa vez entre os tradutores do primeiro livro que participavam do grupo no $\mathrm{Fa}$ cebook. Assim, foi formado um novo grupo de tradutores usando a mesma metodologia de trabalho. O livro "Educar na Era Digital: design, ensino e aprendizagem" de Anthony (Tony) Bates é, originalmente, um livro para ser lido on-line, com diversos links e podcasts que foram, no livro impresso, transformados em QR codes.

Nesse segundo livro, este autor traduziu o capítulo 2, "A natureza do conhecimento e suas implicações para o ensino". Esse capítulo descreve brevemente as principais teorias de aprendizagem, discutindo sua importância para o ensino. Discute, também, "a relação entre nossas visões sobre a natureza do conhecimento e a maneira como decidimos ensinar" (BATES, 2016, p. 81).

Em 2017, convidado por e-mail, este autor participou da tradução que resultou no livro "Educação Aberta Online: pesquisar, remixar e compartilhar". Esse livro trata de educação aberta, que tem como uma de suas características a gratuidade de materiais educacionais que podem, com maior ou menor grau de liberdade, 
ser copiados, modificados, reestruturados e compartilhados com outras pessoas. O próprio livro é um recurso educacional aberto, com licença Creative Commons.

Esse livro se baseia "em cursos online oferecidos pela OpenLearn, ${ }^{2}$ da Open University britânica” (LITTO; MATTAR, 2017, p. 19). O maior problema, dessa vez, foi fazer um livro impresso em língua portuguesa para ser lido off-line a partir de materiais oriundos de cursos on-line em língua inglesa. Esse foi, portanto, um trabalho de remixagem, muito além de uma simples tradução.

Além de situações como a já descrita, de traduções sob encomenda, há também situações nas quais o tradutor se vê diante de um texto que lhe desperta o desejo da tradução motivado pelos mais diversos aspectos, como a constatação da ausência de textos que abordem determinados temas, como podemos observar no relato apresentado a seguir.

\section{$4 \mathrm{O}$ interesse pelo artigo traduzido}

$\mathrm{O}$ artigo $A$ Guide to Conducting a Standalone Systematic Literature Review (OKOLI, 2015) foi compartilhado pelo Professor João Mattar durante um Massive Open Online Course (MOOC) sobre Metodologia do Trabalho Científico, que aconteceu entre março e junho de 2017.

A ideia da tradução do artigo surgiu durante uma das disciplinas que um dos autores do presente artigo ministra no curso de bacharelado em Sistemas de Informação do Instituto Federal do Ceará, campus Crato. Geralmente, ele solicita que, ao final da disciplina "Computador e Sociedade", os alunos produzam um artigo de revisão de literatura sobre um dos conteúdos abordados. Alguns problemas aconteciam em relação a como buscar as fontes, qual a abrangência da revisão, como incluir ou excluir artigos, entre outros. O que acontecia, na verdade, era que eles não sabiam o que é uma revisão de literatura, muito menos como conduzi-la.

2 Disponível em: <http://www.open.edu/openlearn/>. 
Apesar de o artigo defender um modelo de Revisão Sistemática abrangente (de acordo com o artigo, o que é proposto aos alunos assemelha-se mais a uma análise do estado da arte), era, portanto, interessante que eles estivessem familiarizados com a proposta e inclusive participassem de pesquisas desse tipo.

Como é comum que alunos de graduação tenham dificuldades com trabalhos em língua estrangeira, acabam por recorrer a softwares tradutores que, apesar de já terem sido bastante aprimorados nos últimos anos, ainda não são capazes de fugir da literalidade em algumas partes do texto, a tradução mecânica que deixa termos e frases "truncados". Traduzir o artigo foi uma forma de aproximar os alunos de pesquisas estrangeiras.

Alguns termos precisaram de uma análise mais detida, pois nem sempre o que o autor escrevia no texto original fazia sentido quando traduzido para a língua portuguesa. Assim, foi preciso fazer buscas em bancos de dados on-line para que se pudesse encontrar palavras ou expressões que mantivessem, na medida do possível, o sentido cultural original como colocado pelo autor. Com a tradução finalizada, o arquivo traduzido foi enviado para o Professor João Mattar, que atuou como revisor, atentando, inclusive, para questões envolvendo a estrutura e a forma do artigo, fatores importantes que se somam e vão além, agregando valor ao artigo traduzido.

\section{A estrutura e a forma do artigo traduzido}

$\mathrm{O}$ artigo $A$ Guide to Conducting a Standalone Systematic Literature Review tem uma estrutura diferente dos artigos de periódicos brasileiros. Inicialmente, o tamanho é maior que a maioria dos templates brasileiros, com 33 páginas. Além disso, a formatação, especialmente o tipo e tamanho da fonte (Arial, tamanho 10), e o espaçamento simples entre linhas tornaram o trabalho ainda mais demorado. Como um guia para Revisões Sistemáticas de Literatura, ou um tutorial, segue quase todo o corpo do artigo com texto, apresentando apenas uma figura e um quadro, que também foram traduzidos. 
O texto é todo escrito em primeira pessoa, formato que foi mantido na tradução. $\mathrm{O}$ autor deste artigo buscou manter a maior fidelidade possível ao estilo de escrita do autor. O tamanho do artigo tornou a tradução cansativa e alguns erros acabaram passando. Assim, o revisor exerceu uma função importante corrigindo as falhas que não estiveram visíveis ao tradutor. Essa correção não se refere somente aos termos confusos ou ausentes, mas também a erros de grafia na língua portuguesa (principalmente em questões que envolvem o "novo" acordo ortográfico) que podem passar desapercebidos em um trabalho grande demais.

A formatação das citações foi modificada para obedecer às normas da Associação Brasileira de Normas Técnicas (ABNT). Nesse caso, as citações feitas no original nem sempre seguiam um padrão, com o autor às vezes usando a expressão "et al." para trabalhos com três autores e colocando os sobrenomes de todos os autores em trabalhos com mais de três autores. Por exemplo a citação "Rousseau et al." foi traduzida para o formato da norma da ABNT: "ROUSSEAU; MANNING; DENYER, 2008, p. 20”, utilizando os sobrenomes dos três autores e a data, que não se encontra no artigo em inglês.

A lista de referências no final do artigo foi mantida como no original, pois atualizá-las uma a uma (80 referências) para a norma da ABNT seria outro trabalho de tradução.

\subsection{O conteúdo do artigo traduzido}

O texto revela o tipo de revisão que o autor tem em mente, que é diferente do que normalmente se escreve como uma seção de um artigo ou monografia. Ele utiliza o termo "autônoma" para dizer que a revisão proposta é um método que deve ser usado para fazer uma contribuição valiosa à área acadêmica, mas que não se encaixa no tipo de trabalho que geralmente é feito como parte de uma tese ou de um artigo por sua sistematicidade e abrangência.

Para ele, uma Revisão Sistemática de Literatura é um tipo de trabalho com uma rigorosa metodologia, adaptada à área de 
Sistemas de Informação, mas que pode ser aplicada a todas as ciências sociais, especialmente as que utilizam métodos mistos (qualitativos e quantitativos) (OKOLI, 2015).

Nesse contexto, uma Revisão da Literatura rigorosa deve ser (OKOLI, 2015, p. 880, tradução do/s autor/es):

[...] sistemática ao seguir uma abordagem metodológica, explícita na explicação dos procedimentos pelos quais foi conduzida, abrangente na sua extensão de incluir todo o material relevante e, portanto, reprodutível por outros que seguirem a mesma abordagem na revisão do tópico.

$\mathrm{O}$ autor nigeriano segue no modelo tutorial, descrevendo os passos que propõe para a condução de Revisões Sistemáticas de Literatura suficientemente abrangentes, rigorosas e que tragam contribuição à área de pesquisa. Argumenta que "as revisões não deveriam ser apenas bibliografias extensas que listam uma sequência de artigos, mas concentrar-se diretamente em conceitos teóricos e desenvolver, a partir deles, uma história teórica coerente" (op. cit., p. 880 , tradução do/s autor/es).

Assim, há recompensas em se fazer um trabalho que exige tal esforço: a produção de um trabalho de qualidade, valioso tanto para o próprio pesquisador como para outros; pode resultar em publicações de qualidade (IDEM).

O que pode ser encontrado no artigo leva em consideração mais do que a simples coleta de dados ou catalogação de artigos. Demonstra o tratamento para a descrição de um quadro prático rigoroso, o planejamento de um protocolo, o treinamento de revisores e a garantia da qualidade. Importante destacar que esse tipo de revisão pode ajudar a examinar determinada área em busca de uma questão de pesquisa relevante, por meio de mapeamentos sistemáticos ou estudos de escopo.

Um estudo inicial com essa metodologia pode revelar que em determinadas áreas há lacunas que podem ser preenchidas com a concepção de estudos primários. Essa é uma boa estratégia para 
propostas de financiamento de pesquisa, ou até para estudos iniciais na área de pesquisa escolhida (IBIDEM).

\section{Considerações Finais}

Este artigo tratou do relato de experiência na tradução do Guia de Revisão Sistemática de Literatura. O artigo original - $A$ Guide to Conducting a Standalone Systematic Literature Review, publicado originalmente na Communications of the Association for Information Systems - foi escrito por Chitu Okoli, Professor na Concordia University, Montreal, Canadá.

O trabalho de tradução foi dificultado por questões de estrutura do artigo (muito longo, com fonte pequena) e pela dificuldade de relacionar determinados termos à realidade da língua portuguesa. As citações foram transformadas para o padrão brasileiro da ABNT, mas as referências foram mantidas como no original para evitar um trabalho ainda mais difícil de tradução.

Entre os possíveis benefícios resultantes da tradução do artigo estão:

a) aproximar a comunidade de língua portuguesa de trabalhos internacionais;

b) trazer a essa comunidade um método de trabalho que organiza e dá rigor científico às Revisões Sistemáticas de Literatura.

Considerando a responsabilidade de traduzir um texto como esse, foi importante manter a maior fidelidade possível ao que o autor quis transmitir. Apesar das dificuldades em conseguir esse tipo de fidelidade, mais trabalhos devem ser traduzidos para que o público de língua portuguesa possa estar familiarizado com o estado da arte das pesquisas internacionais, sendo possível tanto comparar o nível de nossas investigações, como aprender novos métodos.

\section{Referências}

BATES, Anthony W. Educar na Era Digital: design, ensino e aprendizagem. São Paulo: Artesanato Educacional, 2016 (Coleção tecnologia educacional). 
BENITES, Amanda Cabral Viera; PRIETO, Liliam Cristina Marins. Tradução técnica e condicionantes culturais de um manual de smartphone. In: CONGRESSO NACIONAL DE LINGUAGENS EM INTERAÇÃO, 4, 2013, Maringá. Anais... Maringá: UEM-PLE, 2013, p. 1-12. Disponível em: <http://www. indev.com.br/conali/?l=trabalhos\&id=48>. Acesso em: 23 nov. 2017.

COSTA, Priscilla Thuany C. F. da; NASCIMENTO, Cristiane B. do. The Fortuneteller: Relato de experiência dm prática de tradução em língua inglesa. Cultura e Tradução, v. 4, n. 1, 2017. Disponível em: <http://periodicos.ufpb.br/index. php/ct/article/view/36330> Acesso em: 29 mar. 2018.

LITTO, Fredric M.; MATTAR, João (Org.). Educação Aberta Online: pesquisar, remixar e compartilhar. São Paulo: Artesanato Educacional, 2017 (Coleção tecnologia educacional).

MELLO, Maria Elizabeth C. de. Um relato de experiência de tradução. Cadernos de Letras da UFF, 2013. Dossiê: Tradução n. 48, p. 137-146.

MICCOLI, Laura. Experiências de professores no ensino de língua inglesa: uma categorização com implicações para o ensino e a pesquisa. Linguagem \& Ensino, v. 10, n. 1, p. 47-86, jan./jul. 2007. Disponível em: < http://www.rle.ucpel.tche. br/index.php/rle/article/view/155/122>. Acesso em 24 nov. 2017.

OKOLI, Chitu. A guide to conducting a standalone systematic literature review. Communications of the Association for Information Systems, v. 37, n. 43, p. 879-910, nov. 2015. Disponível em: < http://aisel.aisnet.org/cais/vol37/ iss $1 / 43 />$.

OLIVEIRA, Inês B. de. Aprendendo nos/dos/com os cotidianos a ver/ler/ouvir/sentir o mundo. Educação \& Sociedade, v. 28, n. 98, 2007. Disponível em: <http://www.redalyc.org/html/873/87313707004/> Acesso em: 28 mar. 2018.

PACKER, Abel Laerte. A eclosão dos periódicos do Brasil e cenários para o seu porvir. Educação e Pesquisa, v. 40, n. 2, p. 301-323, abr./jun. 2014. Disponível em: <http://www.redalyc.org/html/298/29830920002/>.

POLCHLOPEK, Silvana; AIO, Michelle de Abreu. Tradução Técnica: armadilhas e desafios. Tradução e Comunicação - Revista Brasileira de Tradutores, n. 19, p. 101-113, abr. 2010. Disponível em: < http://pgsskroton.com.br/seer/index. php/traducom/article/download/2020/1921>. Acesso em 22 nov. 2017.

ZAWACKI-RICHTER, Olaf; ANDERSON, Terry (Org.). Educação a Distância Online: construindo uma agenda de pesquisa, 1. ed. São Paulo: Artesanato Educacional, 2015 (Série Tecnologia Educacional).

Submetido em: 29-3-2018

Aceito em: 2-4-2018 